\title{
Multi-Element Determination of Toxic and Nutrient Elements by ICP-AES after Dispersive Solid-Phase Extraction with Modified Graphene Oxide
}

\author{
Natalia Manousi ${ }^{1}\left(\mathbb{D}\right.$, Eleni Deliyanni ${ }^{2, *(\mathbb{D})}$ and George Zachariadis ${ }^{1, *(\mathbb{C})}$ \\ 1 Laboratory of Analytical Chemistry, Department of Chemistry, Aristotle University of Thessaloniki, \\ 54124 Thessaloniki, Greece; nmanousi@chem.auth.gr \\ 2 Laboratory of Chemical and Environmental Technology, Department of Chemistry, \\ Aristotle University of Thessaloniki, 54124 Thessaloniki, Greece \\ * Correspondence: lenadj@chem.auth.gr (E.D.); zacharia@chem.auth.gr (G.Z.)
}

Received: 7 November 2020; Accepted: 2 December 2020; Published: 5 December 2020

\begin{abstract}
A novel graphene-oxide-derived material was synthesized after modification of graphene oxide with sodium hydroxide and used for the dispersive solid-phase extraction (d-SPE) of different elements $(\mathrm{Pb}, \mathrm{Cd}, \mathrm{Ba}, \mathrm{Zn}, \mathrm{Cu}$ and $\mathrm{Ni}$ ) prior to their determination by inductively coupled plasma atomic emission spectrometry (ICP-AES). The prepared nanomaterial was characterized by $\mathrm{X}$-ray diffraction (XRD), nitrogen adsorption, scanning electron microscopy (SEM), transmission electron microscopy (TEM) and Fourier transform infrared (FTIR) spectroscopy. Full factorial design and Derringer's type desirability function were used for the optimization of the d-SPE procedure. Pareto charts illustrated the effects of each of the examined factors and their interactions on the determination of the elements. Under the optimum conditions, detection limits (LODs) for the elements ranged between 0.01 and $0.21 \mu \mathrm{g} \mathrm{g}^{-1}$, intra-day repeatability $(n=5)$ was lower than $1.9 \%$ and inter-day repeatability $(n=5 \times 3)$ was lower than $4.7 \%$. Relative recovery values ranged between 88.1 and $117.8 \%$. The method was validated and successfully applied for the determination of trace elements in poultry, pork and beef samples from the local market. The proposed method is simple, rapid, sensitive and the novel sorbent can be used at least ten times.
\end{abstract}

Keywords: graphene oxide; metals; meat samples; ICP-AES; dispersive solid-phase extraction; experimental design

\section{Introduction}

Graphene oxide (GO) is considered as a chemical compound with a structure similar to graphene, where oxygen is introduced through chemical oxidation. It is described as a heavily oxygenated nanomaterial with the presence of many functional groups that contain oxygen such as epoxide and hydroxyl groups on its basal plane and carbonyl and carboxyl groups at the edges [1,2]. Due to the presence of these functional groups, GO is able to bind with metal ions, especially with multivalent metal ions, through electrostatic and coordinate approaches [3]. The adsorbed analytes could be eluted by the addition of acids, according to the hydrogen bonding competition [4].

Graphene oxide has been previously used for analytical chemistry purposes, however, in most cases it was anchored onto different surfaces such as silica, monolithic column and $\mathrm{Fe}_{3} \mathrm{O}_{4}$ [5-7]. Moreover, graphene oxide can be functionalized with various polymeric and non-polymeric materials such as polyaniline [4], chitosan [8], ethylenediamine and 1,6-hexanediamine [9], polypyrrole [10], ethylene diamine tetra-acetic acid (EDTA) [11], manganese oxide [12], triethylenetetramine [13] and polyimide [14]. It has been proved several times that functionalization of graphene oxide could increase the adsorption 
capacity for metal ions, however, the investigation of different forms of non-functionalized modified graphene oxide is still a challenge. Reduced graphene oxide (RGO) [15] and oxidized graphene oxide (OGO) [16] are two forms of graphene oxide that have been used for the adsorption of toxic and nutrients metals and rare earth elements, respectively. However, to the best of our knowledge, $\mathrm{NaOH}$-modified graphene oxide $(\mathrm{NaGO})$ has not been used before for the determination of toxic and nutrient elements.

Metals are a group of important pollutants because of their potential toxic and carcinogenic effects. In general, they are refractory and non-degradable, and they tend to accumulate in the organisms. Some metals can be toxic at low concentration and, as a result, their presence in the aquatic environment represents water pollution [17]. Meat and meat products are important for human diet in many parts of the world since they provide the well-known trace element contents. Therefore, there is a great concern about the effects of anthropogenic pollution on the ecosystems [18]. Chromium, iron, copper and zinc are essential elements for human health, and they are playing a vital role in human metabolism [19]. On the other hand, lead and cadmium are potential harmful metals and environmental pollution is the main cause of their presence in the food chain. Nickel is a moderately toxic element as compared with other transition metals [20]. Moreover, aluminum and barium are non-essential elements and their biological function for living organisms is unknown [21,22]. A wide variety of inductively coupled plasma atomic emission spectroscopy (ICP-AES) methods have been reported in the literature regarding the determination of toxic and nutrient metals in meat and meat products after acidic digestion [18,23-27].

In this work, different graphene-oxide-derived materials were examined for the preconcentration of metals from meat samples. Following the selection of the optimum material for dispersive solid-phase extraction (d-SPE), experimental design methodology was used for the optimization of the extraction process. Compared to the traditional "one variable at a time" approach, which is more time consuming, experimental design or design of experiment (DoE) is a simpler, quicker and more reliable methodology, since it provides the advantage of multivariate optimization [28,29]. Factorial design is a popular statistical process for multivariate optimization that is used in analytical chemistry because of its usefulness in the identification of the significant variables and the optimum experimental conditions. The main advantage of multivariate designs is the allowance of the simultaneous study of different factors' effects together with the interactions' effects among the factors. In order to optimize the extraction recovery of the different metals, a compromise has to be made [30]. Derringer's desirability function was employed to provide satisfactory solution to this challenge using multi-criteria methodology [31,32].

To the best of our knowledge, there is no published method for the comparison of different graphene oxide forms regarding their use for the preconcentration of $\mathrm{Pb}, \mathrm{Cd}, \mathrm{Ba}, \mathrm{Zn}, \mathrm{Cu}$ and $\mathrm{Ni}$ in meat samples. As a result, the aim of this study was to evaluate different graphene oxide novel derivatives for the d-SPE prior to ICP-AES analysis for the determination of toxic and nutrient elements in meat samples combined with full factorial experimental design and Derringer's type desirability function for optimization. After validation, the proposed d-SPE-ICP-AES method was used for the determination of toxic and nutrient elements in pork, beef and poultry samples.

\section{Experimental}

\subsection{Materials and Methods}

All chemicals used were of analytical grade. Nitric acid $\left(\mathrm{HNO}_{3}\right) 65 \%$ and ammonia solution $25 \%$ were supplied by Merck (Darmstadt, Germany). High-purity double-distilled water, prepared by passing tap water through two ion exchange columns, was used. Stock standard solutions $\left(1000 \mathrm{mg} \mathrm{L}^{-1}\right)$ of each element were also supplied by Merck (Darmstadt, Germany). Working standard solutions were daily prepared by serial dilutions of the stock solutions in $2 \% v / v \mathrm{HNO}_{3}$.

The chemicals used for the preparation of the material, including graphite, sulfuric acid $\left(\mathrm{H}_{2} \mathrm{SO}_{4}\right)$ potassium permanganate $\left(\mathrm{KMnO}_{4}\right)$, hydrogen peroxide and sodium hydroxide $(\mathrm{NaOH})$, 
were purchased from Sigma-Aldrich (St. Louis, MO, USA). All the reagents were of analytical grade (puriss. pa. $\geq 98.5 \%$ ). Meat samples (beef, chicken and pork) were supplied from the local market in Thessaloniki, Greece.

\subsection{Preparation of Graphite Oxide}

Graphite oxide was synthesized after oxidation of graphite by a modified Hummers method [33]. For the synthesis, $10 \mathrm{~g}$ of graphite was dispersed in $230 \mathrm{~mL}$ of $\mathrm{H}_{2} \mathrm{SO}_{4}(98 \% w / w)$ in a $500 \mathrm{~mL}$ flask placed in an ice bath. The dispersion was stirred for $30 \mathrm{~min}$, followed by the dropwise addition of $30 \mathrm{~g}$ of $\mathrm{KMnO}_{4}$ solution at a controlled rate preventing a temperature rise higher than $20^{\circ} \mathrm{C}$. The brownish slurry produced was diluted with $230 \mathrm{~mL}$ of water and further with $1400 \mathrm{~mL}$ of water followed by $100 \mathrm{~mL}$ of hydrogen peroxide $(30 \% w / w)$. After $24 \mathrm{~h}$, purification in dialysis tubes (D9402-100FT Sigma-Aldrich) took place and the mixture was centrifuged, rinsed with $\mathrm{HCl}$ and double deionized water. Subsequently, filtration and freeze-drying took place. Finally, graphite was obtained as a brown powder.

\subsection{Preparation of $R G O$}

For the reduction of graphene oxide, the material was dispersed into $100 \mathrm{~mL}$ of water where an $80 \% w / w$ aqueous hydrazine hydrate solution was added. The obtained dispersion stayed under stirring at $95^{\circ} \mathrm{C}$ for $5 \mathrm{~h}$. After filtration and distilled water washing, freeze-drying of the product took place [34].

\subsection{Preparation of $\mathrm{NaGO}$}

For the synthesis of $\mathrm{NaGO}, 2 \mathrm{~g}$ of graphite oxide was dispersed in $175 \mathrm{~mL}$ of deionized water and the dispersion was sonicated for $60 \mathrm{~min}$. Then, $35 \mathrm{~mL}$ of freshly prepared sodium hydroxide solution (concentration: $0.5 \mathrm{M}$ ) was gradually added under stirring. After $3 \mathrm{~h}$ of stirring, the dispersion was transferred into a $100 \mathrm{~mL}$ round-bottomed flask and was refluxed for $60 \mathrm{~min}$ at $90{ }^{\circ} \mathrm{C}$. The obtained product was centrifuged and washing with deionized water and absolute ethanol took place, followed by freeze-drying.

\subsection{Instrumentation}

A Perkin-Elmer Optima 3100XL axial viewing ICP-AES was used for the analysis. The analytical wavelengths that were recorded are: Ba $233.527 \mathrm{~nm}$ (II), Cd $226.502 \mathrm{~nm}$ (II), Cu $324.752 \mathrm{~nm}$ (I), Ni $232.003 \mathrm{~nm}$ (I), Pb $217.000 \mathrm{~nm}$ (I); Zn $213.857 \mathrm{~nm}$ (I). Herein, (I) indicates that an atomic line is used, while (II) indicates that an ionic line is used. Table S1 shows the instrument's operating conditions. A cyclonic spray chamber was used in order to avoid the entrance of possibly remaining sorbent nanoparticles into plasma.

For the digestion procedure, Teflon ${ }^{\circledR}$ (DuPont, DE, USA) vessels and a steel autoclave heated in a six-position aluminum block (Berghof, BTR,941, Eningen, Germany) were used. The maximum working volume of the vessels was $50 \mathrm{~mL}$ with a maximum temperature of $180^{\circ} \mathrm{C}$.

All sample preparation apparatus, glassware, digestion vessels and storage bottles were soaked in $10 \% v / v \mathrm{HNO}_{3}$ for at least one day and washed extensively with double de-ionized water prior to their use to avoid contamination. Crucibles were immersed in $20 \% v / v$ hydrochloric acid for about $48 \mathrm{~h}$ and washed with double de-ionized water several times.

For the sample preparation, a METROHM 654 pH-meter (METROHM AG, Herisau, Switzerland) and a Sartorius 1601 Mp8 Analytical Balance (Sartorius AG, Gottingen, Germany) were employed, while a HERMLE Z 320 centrifuge (Hermle Labortechnik GmbH, Wehingen, Germany) was used for the phase separation during the d-SPE process.

X-ray diffraction (XRD) patterns were obtained on a Philips PW 1820 diffractometer with a Cu $\mathrm{K} \alpha$ radiation, from 293 to $353 \mathrm{~K}$ in order to identify the crystalline phase of the materials. Surface area and pore structure measurements were testified by nitrogen adsorption-desorption isotherms 
at liquid $\mathrm{N}_{2}$ temperature of $77 \mathrm{~K}$ by a Quantachrome Autosorb-1C automated adsorption instrument. The surface morphology was illustrated by a scanning electron microscope (JEOL JSM 7600F, Peabody, MA, USA) and a transmission electron microscope (JEOL JEM 2100, Peabody, MA, USA). The surface chemistry of the examined materials was determined by Fourier transform infrared (FTIR) spectroscopy recorded on a Perkin-Elmer 2000 FTIR spectrometer (Dresden, Germany) using KBr disks. The spectra, presented at transmittance mode, were recorded from 4000 to $400 \mathrm{~cm}^{-1}$.

\subsection{Validation}

Linearity for the proposed method was assessed by linear regression analysis. Calibration curves for standard solutions and for aqueous solutions after the d-SPE procedure were constructed by plotting the intensity of the target analytes to their nominal concentration. Experiments were conducted at triplicates. Least square linear regression analysis was employed for the calculation of the slope, the intercept, and the coefficient of determination for each metal. The detection limits (LODs) and quantification limits (LOQs) were estimated as the concentration equal to 3 and 10 times the standard deviation of the measurement divided by the slope of calibration line of the aqueous standard or of standard addition for each analyte, respectively [22,35].

Enrichment factor (EF) was determined as the ratio of metal ions' concentration in the solution after elution to the initial nominal concentration in the aqueous sample. Percent extraction recoveries were calculated by comparing the found concentration and the theoretical concentration followed by multiplying by $100[35,36]$.

The accuracy of the d-SPE-ICP-AES method was assessed in terms of bias between the real and experimentally determined concentrations in spiked samples, since there was no available certified reference material (CRM) on hand. Precision was estimated by analyzing spiked meat samples. For this purpose, intra-day repeatability was assessed by analyzing in five replicates spiked samples, while inter-day precision was determined by analyzing in triplicate-spiked samples of the same concentration levels in 5 days [35].

\subsection{Sample Preparation}

Three kinds of meat samples (beef, chicken, pork) were subjected to the d-SPE method. For the pretreatment of the samples, about $1 \mathrm{~g}$ of each meat sample was ground and placed in Teflon ${ }^{\circledR}$ vessels for acidic digestion. Subsequently, five milliliters of $65 \%$ nitric acid was added and the vessel was placed in the autoclave and heated at $140{ }^{\circ} \mathrm{C}$ for $90 \mathrm{~min}$. The digestion procedure was complete for all matrices, without any remaining organic or other undissolved residues. After cooling of the digests, the vessels were opened and, after adjusting the $\mathrm{pH}$ value of the solution to 5 with diluted $\mathrm{HNO}_{3}$ and $\mathrm{NH}_{3} \cdot \mathrm{H}_{2} \mathrm{O}$, the sample solution was transferred into a $50 \mathrm{~mL}$ volumetric flask-the volume was made up to the mark with water and the metals were extracted by the d-SPE procedure. These final solutions are of the same nature, i.e., slightly acidic clear aqueous solutions containing free metal ions. Therefore, the validation results that are described are valid for all types of the examined meat samples.

The blank solutions were prepared by using double-distilled water with no addition of the analytes and they were subjected to the same procedure described above.

\section{8. $d$-SPE Process}

Initially, $50 \mathrm{~mL}$ of the sample solution, the $\mathrm{pH}$ value of which was adjusted to 5 with diluted $\mathrm{HNO}_{3}$ and $\mathrm{NH}_{3} \cdot \mathrm{H}_{2} \mathrm{O}$, was transferred into a centrifugation tube for the d-SPE process. Accordingly, $25 \mathrm{mg}$ of $\mathrm{NaGO}$ was placed in the aqueous solution and dispersed by ultrasonic radiation for $5 \mathrm{~min}$. Subsequently, isolation of the material took place by centrifugation at $2900 \times g$. The effluent was discarded and the analytes were desorbed from the NaGO sorbent were desorbed from the NaGO sorbent with $2.5 \mathrm{~mL}$ of $1.5 \mathrm{M} \mathrm{HNO}_{3}$ by ultrasonication for $5 \mathrm{~min}$, the mixture was centrifuged, and the eluate was injected into the ICP-AES instrument. Bis-distilled water (with $\mathrm{pH}$ adjusted to 5) was subjected to the above-mentioned procedure and was used as the blank solution for the d-SPE procedure. 


\section{Results and Discussions}

\subsection{Material Characterization}

The X-ray diffraction measurements for the adsorbents under examination were performed in a range of $2 \theta$ from $5^{\circ}$ to $40^{\circ}$ and the relative patterns are presented in Figure 1a. For GO, the sharp $\left(\begin{array}{lll}0 & 0 & 2\end{array}\right)$ diffraction peak at $2 \theta=10.6^{\circ}$ indicates a well-defined layered structure with an interlayer spacing, as determined by Bragg's law, of about $0.81 \mathrm{~nm}$ [37]. For RGO and NaGO adsorbents, the diffraction peak at $2 \theta=23.5^{\circ}$ indicates stacked graphene layers. The Scherrer equation was used for the estimation of the average diameter of stacking layers. GO, as was estimated by the Scherrer equation, was found to consist of eight graphene layers while RGO consisted of 3-4 layers and NaGO of about three [38], with crystallite average size about $1.34 \mathrm{~nm}$ for RGO and 1.21 for NaGO. Moreover, the modification of graphene oxide with sodium hydroxide was confirmed by energy-dispersive X-ray spectroscopy (EDS) spectra where Na was found on the sample's surface (Figure 1c). From the scanning electron microscopy (SEM) micrographs (Figure 1b), it can be concluded that the NaGO sorbent displayed typical rippled and crumpled surfaces, which are indicative of graphene. Wrinkling and ridge formation were observed both in SEM (Figure 1b) and transmission electron microscopy (TEM) (Figure 1d) images and they could be the reason for the enhanced porosity of the NaGO sorbent.
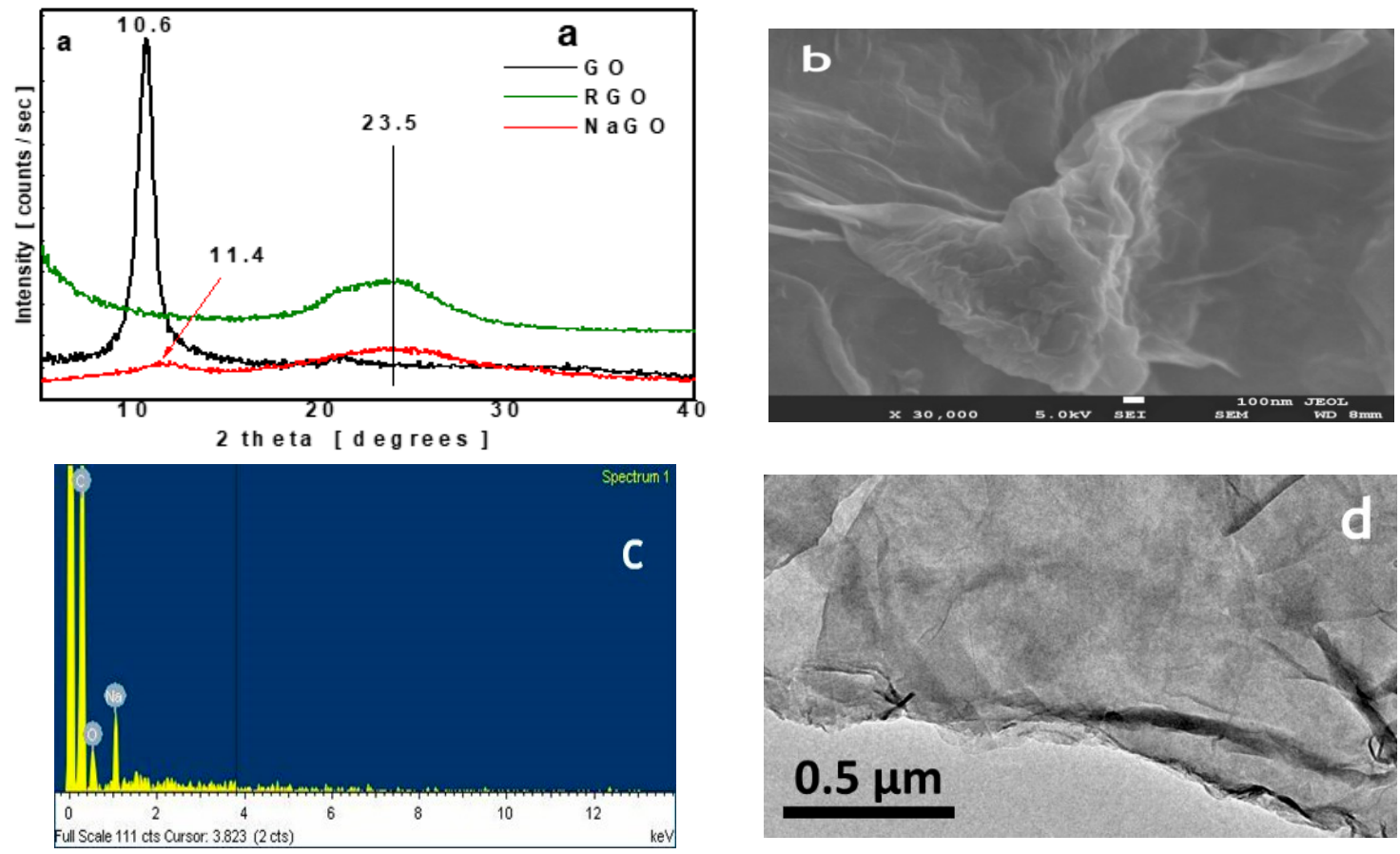

Figure 1. (a) XRD patterns for GO, RGO and NaGO. (b) SEM image for NaGO, (c) EDS results for $\mathrm{NaGO}$ and (d) TEM image for NaGO.

\subsection{Optimization of Dispersive Solid-Phase Extraction Procedure}

\subsubsection{Selection of the Adsorbent}

Initially, three graphene-oxide-based materials were evaluated for the extraction of metals from aqueous sample solutions. For the comparison of the materials, stable adsorption and desorption conditions were used. The examined $\mathrm{pH}$ ranges were between 2 and 6 . The $\mathrm{pH}$ of the solution is a critical parameter for the toxic and nutrient element adsorption onto carbonaceous materials. The extraction recoveries that were obtained for the examined elements at preliminary experiments with GO, RGO and NaGO are shown at Figure 2. 

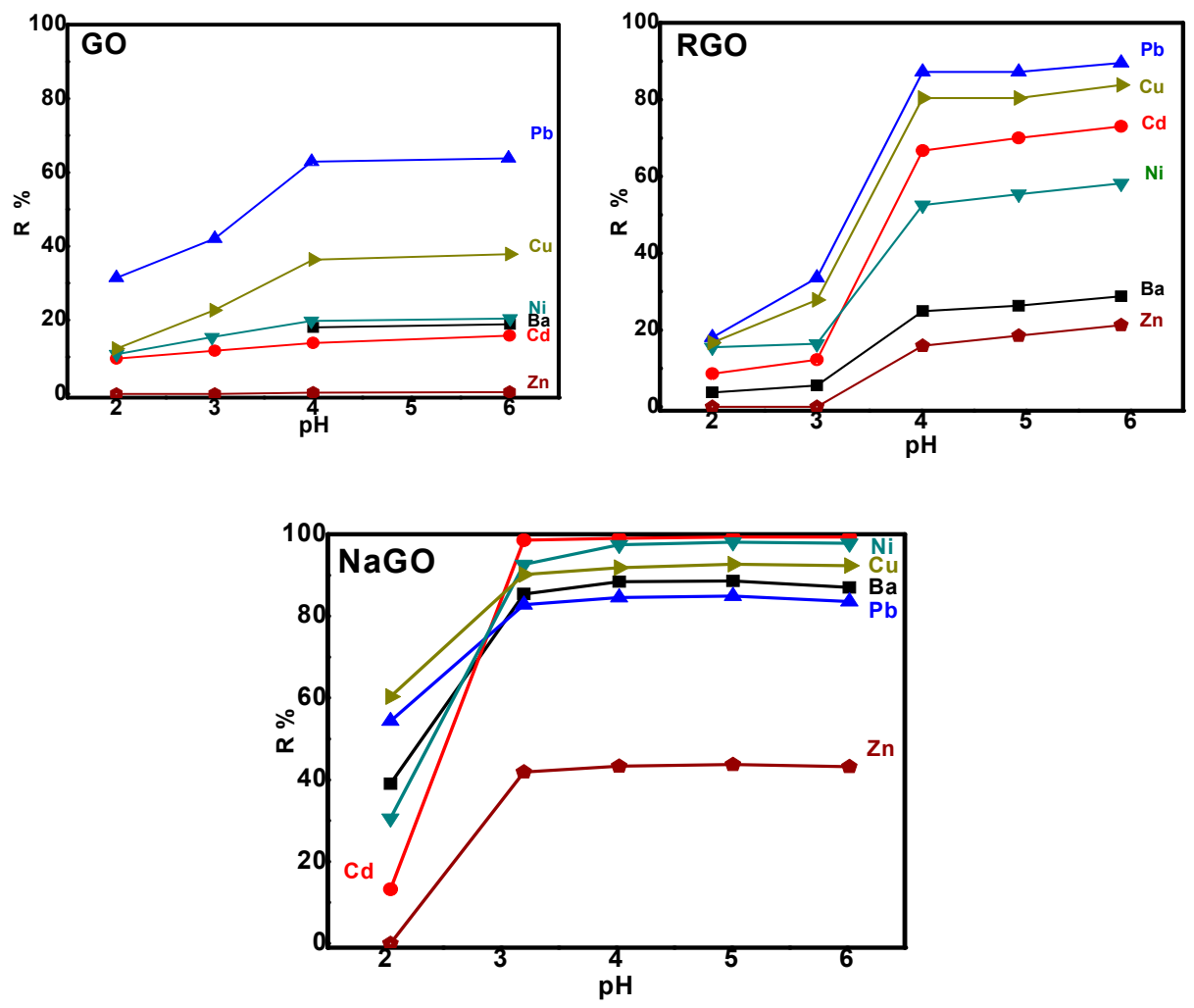

Figure 2. Extraction recoveries at different $\mathrm{pH}$ values with graphene oxide (GO), reduced graphene oxide (RGO) and $\mathrm{NaOH}$ modified graphene oxide ( $\mathrm{NaGO})$.

With GO, the removal of the metal ions at low values of $\mathrm{pH}$, for the examined metals (except from $\mathrm{Pb}$ ), was found to be less than $20 \%$. However, with the increase in $\mathrm{pH}$ to the range of $4-6$, the metal removal increased. As a result, that was the optimum $\mathrm{pH}$ range for GO, however, the removal of metal ions was still low $(>50 \%)$. In order to explain the effect of $\mathrm{pH}$ on the adsorption of metal ions onto carbonaceous materials, both the metal speciation in solution and the surface acidity of these materials must be taken into account. In principle, from the results regarding metal speciation, the $\mathrm{pH}$ range where metals are present in their cationic form and no precipitation occurs can be determined. At low values of $\mathrm{pH}$, the surface groups of graphene oxide that contain oxygen are protonated. As a result, suppression of adsorption might happen, due to the complexation among the positively charged metal ions and the functional groups of graphene oxide that carry equal charge, since they may repel each other. On the other hand, as the $\mathrm{pH}$ value of the solution increases, adsorption is enhanced, due to the interaction of metal ions with the surface of graphene oxide which is negatively charged. This has also been observed for the influence of the $\mathrm{pH}$ value on the adsorption of metal ions onto activated carbons $[39,40]$.

Similar results were observed for RGO since the $\mathrm{pH}$ range of 4-6 was also found to be the optimum range for metal removal with this material. Compared to the GO, with the RGO adsorbent, the metal removal increased and reached $50-90 \%$ for some metal ions. This could be attributed to the two-dimensional (2D) structure of RGO and the simpler adsorption of metal ions through Cp-cation interactions on this material, compared with the GO that exhibits a three-dimensional (3D) structure. These interactions are electrostatic based between the metal cations and the quadrupole moment of the aromatic rings of the carbonaceous material, which may be due to a bond between the positive charge (i.e., $\mathrm{H}_{3} \mathrm{O}^{+}$ions) and the delocalized $\pi$ electrons of the aromatic rings [41]. If the delocalized $\pi$ electrons are considered as a Lewis base, the interaction could be a cation exchange interaction among $\left(-\mathrm{C} \pi-\mathrm{H}_{3} \mathrm{O}^{+}\right)$and metal ions and this would, thus, be a plausible mechanism [42].

$$
\mathrm{C} \pi-\mathrm{H}^{+}+\mathrm{M}^{+} \rightarrow \mathrm{C} \pi-\mathrm{M}^{+}+\mathrm{H}^{+}
$$


With $\left(-\mathrm{C} \pi-\mathrm{H}_{3} \mathrm{O}^{+}\right)$to be after the equation:

$$
-\mathrm{C} \pi+2 \mathrm{H}_{2} \mathrm{O} \rightarrow \mathrm{C} \pi-\mathrm{H}_{3} \mathrm{O}^{+}+\mathrm{OH}^{-}
$$

Different results were observed for NaGO. From Figure 2 it can be clearly observed that the use of $\mathrm{NaGO}$ led to higher recovery values and higher range of $\mathrm{pH}$ scale where extraction recoveries are considered robust. The optimum $\mathrm{pH}$ range, in which the metal removal was the highest, was found to be 3-6, while the metal removal increased and reached almost $100 \%$ for some metals. This could happen not only due to the 2D structure of $\mathrm{NaGO}$ but also due to the simpler adsorption through $\pi-\pi$ stacking on this sorbent and due to ion exchange. During the GO modification, $\mathrm{NaOH}$ reacts with oxygen surface functional groups and replaces $\mathrm{H}^{+}$. These phenolate forms can facilitate the replacement of $\mathrm{Na}^{+}$with metal ions, even at lower $\mathrm{pH}$ values increasing this way the metal adsorption onto NaGO surface.

The mechanism for the adsorption of the metal ions was also confirmed by FTIR measurements, that were obtained for graphene oxide and $\mathrm{NaGO}$ prior and after adsorption of metals. The FTIR measurements are presented in Figure 3.

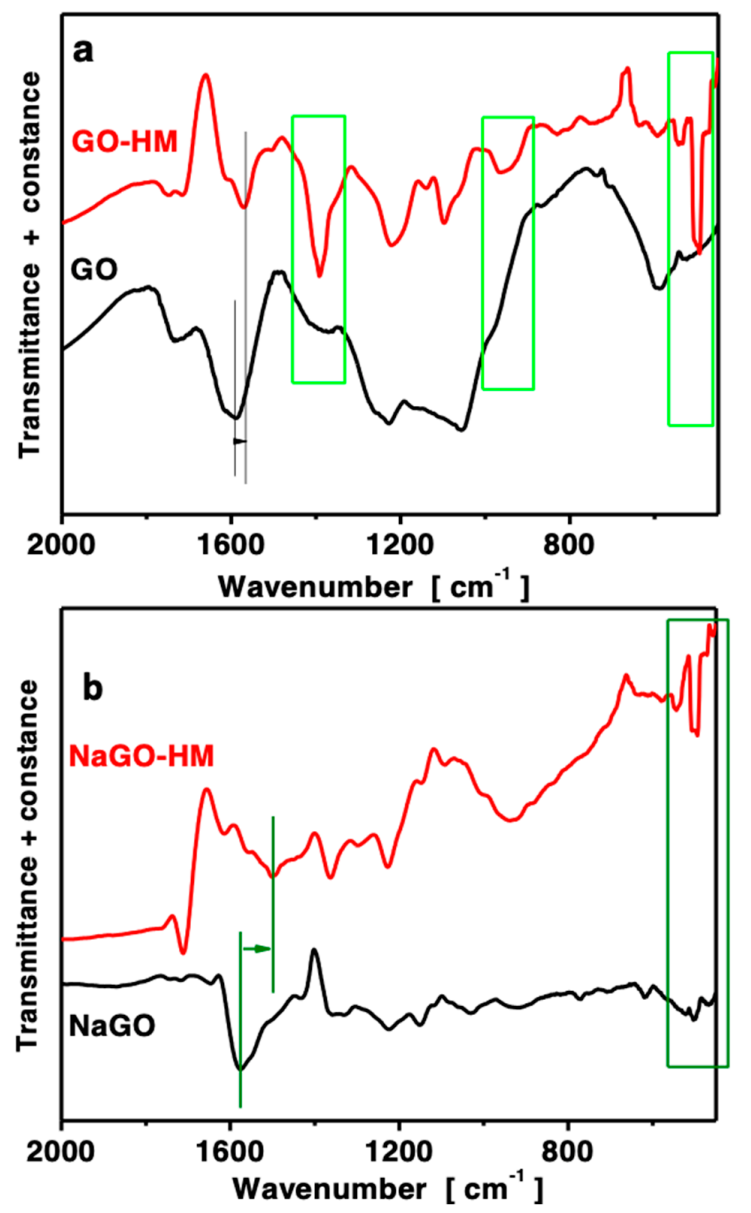

Figure 3. FTIR spectra for GO (a) and $\mathrm{NaGO}(\mathbf{b})$ before and after metal ion adsorption (HM).

For graphene oxide, the bands at 1060,1240, 1380 and $1730 \mathrm{~cm}^{-1}$ could be due to the stretching vibration of the $\mathrm{C}-\mathrm{O}$ (alkoxy) $\mathrm{C}-\mathrm{O}-\mathrm{C}$ (epoxy) $\mathrm{O}-\mathrm{C}=\mathrm{O}$ (carboxyl) and $\mathrm{C}=\mathrm{O}$ bonds, respectively [43,44], while the band at $1625 \mathrm{~cm}^{-1}$ can be attributed to the $C=C$ skeletal vibrations that come from the aromatic ring $[45,46]$. For $\mathrm{NaGO}$, it is seen that these bands due to oxygen containing groups were eliminated, indicating that the oxygen functional groups reacted with $\mathrm{NaOH}$. This was confirmed by EDS spectra where Na was found on the sample's surface (Figure 1c). 
From FTIR results after metal adsorption onto GO, it is seen that the band at $1740 \mathrm{~cm}^{-1}$, attributed to the stretching vibration of $\mathrm{C}=\mathrm{O}$ of carboxyl groups, the band at $1150 \mathrm{~cm}^{-1}$, due to phenolic $\mathrm{O}-\mathrm{H}$ bending mode and the band at $980 \mathrm{~cm}^{-1}$, related to epoxy groups, were no longer visible. As a result, it was indicated that these groups were involved in the metals' adsorption. The following equations describe the interactions [40]:

$$
\begin{gathered}
2(\mathrm{COH})+\mathrm{M}^{2+} \rightarrow\left(\mathrm{CO}^{-}\right)_{2} \mathrm{M}^{2+}+2 \mathrm{H}^{+} \\
2 \mathrm{CO}^{-}+\mathrm{M}^{2+} \rightarrow\left(\mathrm{CO}^{-}\right)_{2} \mathrm{M}^{2+}
\end{gathered}
$$

where $\mathrm{C}$ represents the sorbent's surface.

At strong acidic conditions ( $\mathrm{pH}=2)$, the interaction that is most likely to occur is the weak bonds between the (-OH) groups of graphene oxide and the metal ions (Equation (1)). When the $\mathrm{pH}$ of the sample increases from three to six, the surface functional groups that contain oxygen $(-\mathrm{COOH},-\mathrm{OH})$ are deprotonated and strong electrostatic attraction between them and the divalent metal cations $\left(\mathrm{M}^{2+}\right)$ can take place (Equation (2)).

Additionally, for the GO spectrum after metal adsorption, the band at $1615 \mathrm{~cm}^{-1}$ was shifted to $1630 \mathrm{~cm}^{-1}$. This can be mainly attributed to an ion-exchange reaction among the metal ions and the delocalized protonated $\pi$-electrons of the graphene layer $\left(-\mathrm{Cp}-\mathrm{H}_{3} \mathrm{O}^{+}\right)$[47]. This was also the case for the sorption of cadmium(II), mercury(II), chromium(III) and lead(II) on activated carbons [47-51]. In the spectrum of NaGO after metal ion adsorption, this shift was more pronounced (from 1580 to $1500 \mathrm{~cm}^{-1}$ ) indicating that the ion-exchange reaction among the metal ions and the delocalized protonated $\pi$-electrons of the graphene layer was an important mechanism of adsorption for this 2D sorbent, where metal ions could more easily approach and be sorbed on its graphene layers. Thus, FTIR results suggest that adsorption of metal ions onto graphene oxide and NaGO surface occurs through an ion-exchange reaction between the metal ions and the delocalized protonated $\pi$-electrons of the graphene layer, as well as through weak bonds and/or electrostatic forces among the oxygen containing groups of graphene oxide and $\mathrm{NaGO}$ and the metal ions.

Based on these results, finally, $\mathrm{NaGO}$ material was chosen for further examination and an adsorption $\mathrm{pH}$ value of 5 was employed for the whole experimental process.

\subsubsection{Selection of Emission Lines}

With the herein used ICP-AES instrument, multiple spectral lines can be used for the quantification of the target analytes. The selection of the emission line was based on the absence of spectral interferences in combination with the higher sensitivity, i.e., higher slope of calibration curve for the standard solutions. Finally, the following emission lines were chosen: Ba 233.527 II; Cd 226.502 II; Cu 324.752 I; Ni 232.003 I; Pb 217.000 I; Zn 213.857 I.

\subsubsection{Selection of Adsorption and Desorption Volume}

The adsorption volume $\left(\mathrm{V}_{\text {adsorption }}\right)$ and desorption volume $\left(\mathrm{V}_{\text {desorption }}\right)$ of the d-SPE method were selected based on the requirements for compatibility with the sample preparation technique and the ICP-AES system. Therefore, the sample volume was set to $50 \mathrm{~mL}$, which is the lowest quantity after the sample digestion that can be employed for $\mathrm{pH}$ adjustment. Similarly, the desorption volume was set to $2.5 \mathrm{~mL}$, which is the lowest quantity required for the injection into the used ICP-AES instrument.

\subsubsection{Full Factorial Experimental Design for the Optimization of the d-SPE Method}

The 2-Level factorial design ( $2^{\mathrm{k}}-\mathrm{FD}, \mathrm{k}$ is the factor's amount) is the most commonly used factorial design. Herein, the selected factors were investigated at two levels, i.e., a high and a low level which are coded as " + " or " +1 " and " - " or " -1 ", respectively. In this work, the following factors were optimized: mass of $\mathrm{NaGO}(\mathrm{m})$, time of adsorption $\left(\mathrm{t}_{\mathrm{ads}}\right)$, time of desorption $\left(\mathrm{t}_{\mathrm{des}}\right)$ and concentration of the acid used as eluent $\left(\mathrm{C}_{\text {acid }}\right)$. Therefore, 16 experiments were required, which were conducted 
in duplicates and two center points were added, resulting in a total sum of 34 experiments. Table S2 shows the examined levels and the matrix that was obtained. The run order of the experiments was randomized in order to eliminate systematic errors.

The regression models for all metals were found to be statistically significant. Criteria for rejecting an outlier, coming from the errors' normal distribution, require that the standardized residuals must exhibit mean zero and unit variance [31]. Therefore, the standardized residuals must have values up to \pm 3 . If higher standardized residuals were observed, they were considered as outliers and they were discarded from further statistical analysis. For the construction of the mathematical model, ANOVA was used to evaluate the statistical significance of each variable.

For the examined metals, their linear term, their quadratic and interactions were studied for a confidence level $95 \%$. Thus, $\mathrm{p}$ values lower than 0.05 mean that the factor or the interaction of factors has a statistically significant effect. Table S3 shows the regression analysis for the six elements. Bold letters indicate the significant factors and/or their interactions. The pareto charts for $\mathrm{Ba}, \mathrm{Cd}$, $\mathrm{Ni}, \mathrm{Cu}, \mathrm{Zn}$ and $\mathrm{Pb}$ are presented on Figure S1. As can be observed, different experimental factors (i.e., acid concentration for $\mathrm{Cd}, \mathrm{Ba}, \mathrm{Cu}$ and $\mathrm{Zn}$, as well as sorbent mass for $\mathrm{Zn}, \mathrm{Cu}$ and $\mathrm{Ni}, \mathrm{t}_{\mathrm{des}}$ for $\mathrm{Ba}$ and $\mathrm{Ni}$ and $\mathrm{t}_{\mathrm{ads}}$ for $\mathrm{Ni}$ ) and interactions of factors (e.g., interaction of sorbent mass and desorption time for $\mathrm{Ni}$ ) were found to be significant. In principle, the quantity of the sorbent has to be sufficient to provide adsorption of the target analytes, the adsorption and desorption time have to be sufficient to achieve adsorption and desorption of the analytes, respectively, while the concentration of the acid has to be sufficient to provide desorption of the adsorbed metal ions.

From the experimental data, it is clear that there is a different behavior under the specific experimental conditions between the examined analytes. Thus, in order to obtain the optimum conditions, a compromise was conducted using Derringer's Desirability Function. Therefore, the experimental conditions that resulted in the optimum extraction recovery for the examined metals are: mass $=25 \mathrm{mg}, \mathrm{t}_{\mathrm{ads}}$ and $\mathrm{t}_{\mathrm{des}}$ : $5 \mathrm{~min}$, nitric acid concentration: $1.5 \mathrm{M}$. It is important to mention that hydrochloric acid $(\mathrm{HCl})$ and acetic acid $\left(\mathrm{CH}_{3} \mathrm{COOH}\right)$ were also tested at the concentration of $1.5 \mathrm{M}$. Differentiation of the \% extraction recoveries was $\pm 10 \%$ for the examined metals. Therefore, similar behavior of the three examined eluents was observed and nitric acid was finally chosen.

\subsection{Sorbent Capacity}

In order to evaluate the adsorption capacity of $\mathrm{NaGO}$, which is an important factor for its performance, the method that was recommended by Angel Maqulelra and Puchades was employed [52]. For this purpose, the experiments were carried out under the optimum d-SPE conditions. The analytes were detected in the effluents by ICP-AES. The adsorption capacities of NaGO are presented at Table 1, as well as the adsorption capacity of other reported materials. As can be seen, the adsorption capacity for most metals is considered satisfactory for the analysis of food samples regarding the levels on real samples. Higher adsorption capacity was reported for $\mathrm{Zn}, \mathrm{Cu}$ and $\mathrm{Pb}$. The good adsorption capacity of the proposed adsorbent can be attributed to its high surface area and to the efficient interaction between the material and the examined elements.

Table 1. Comparison of the adsorption capacities of $\mathrm{NaGO}$ and other sorbents reported in the literature.

\begin{tabular}{|c|c|c|c|c|c|c|c|}
\hline \multirow[b]{2}{*}{ Analyte } & \multicolumn{7}{|c|}{ Adsorption Capacity (mg g ${ }^{-1}$ ) } \\
\hline & NaGO (This Work) & GO-Silica [53] & $\mathrm{Al}_{2} \mathrm{O}_{3}[54]$ & $\begin{array}{l}\text { Sol Gel } \\
\text { 3-Mercaptopropyltrimethoxysilane } \\
\text { Silica [55] }\end{array}$ & $\begin{array}{l}\text { Zn-Molecularly } \\
\text { Imprinted } \\
\text { Polymer [56] }\end{array}$ & $\mathrm{GO} / \mathrm{SiO}_{2}[57]$ & GO [58] \\
\hline $\mathrm{Cu}$ & 40.3 & 5.5 & - & - & - & 6.0 & - \\
\hline $\mathrm{Zn}$ & 228.1 & - & - & - & 68.6 & - & - \\
\hline $\mathrm{Ba}$ & 4.8 & - & - & - & - & - & - \\
\hline $\mathrm{Cd}$ & 4.3 & 16 & 1.90 & - & - & - & - \\
\hline $\mathrm{Ni}$ & 3.9 & 7.4 & 1.19 & - & - & - & 7.0 \\
\hline $\mathrm{Pb}$ & 24.9 & 25 & - & 1.19 & - & 13.6 & - \\
\hline
\end{tabular}

For zinc, the capacity was higher than in ref. [56] and for copper the capacity was higher than in ref. [53,57]. For nickel, the capacity was higher than in ref. [54] but lower than the one reported in 
ref. $[53,58]$. For cadmium, the capacity was higher than in ref. [54] but lower than the one reported in ref. [53]. Finally, for lead, the capacity was higher than in ref. [55,57] and similar to the one reported in ref. [53].

\subsection{Effect of Co-Existing Ions}

For the estimation of the method's tolerance limit towards the ions that co-exist in the sample matrix, the effect of coexisting ions was studied. In order to have satisfactory tolerance, the analyte recovery must remain between 85 and $115 \%$ in the presence of other ions. For $\mathrm{Cu}$ and $\mathrm{Pb}$, the material shows satisfactory selectivity for $5000 \mathrm{mg} \mathrm{L}^{-1} \mathrm{~K}^{+}, 5000 \mathrm{mg} \mathrm{L}^{-1} \mathrm{Na}^{+}, 100 \mathrm{mg} \mathrm{L}^{-1} \mathrm{Ca}^{2+}$ and $\mathrm{Mg}^{2+}$, $500 \mu \mathrm{g} \mathrm{L}^{-1} \mathrm{As}^{3-}, 500 \mu \mathrm{g} \mathrm{L}^{-1} \mathrm{Bi}^{3+}, 15,000 \mathrm{mg} \mathrm{L}^{-1} \mathrm{Cl}^{-}$and $15,000 \mathrm{mg} \mathrm{L}^{-1} \mathrm{NO}_{3}{ }^{-}, 1000 \mathrm{mg} \mathrm{L}^{-1} \mathrm{SO}_{4}{ }^{2-}$, $10,000 \mathrm{mg} \mathrm{L}^{-1} \mathrm{NH}_{4}{ }^{+}$for their quantification. However, for the remaining analytes, i.e., $\mathrm{Ba}, \mathrm{Cd}$, $\mathrm{Ni}$ and $\mathrm{Zn}$, the tolerance limit for co-existing ions was found to be $1000 \mathrm{mg} \mathrm{L}^{-1} \mathrm{~K}^{+}, 1000 \mathrm{mg} \mathrm{L}^{-1} \mathrm{Na}^{+}$, $50 \mathrm{mg} \mathrm{L}^{-1} \mathrm{Ca}^{2+}$ and $\mathrm{Mg}^{2+}, 500 \mu \mathrm{g} \mathrm{L}^{-1} \mathrm{As}^{3-}, 500 \mu \mathrm{g} \mathrm{L}^{-1} \mathrm{Bi}^{3+}, 15,000 \mathrm{mg} \mathrm{L}^{-1} \mathrm{Cl}^{-}$and $15,000 \mathrm{mg} \mathrm{L}^{-1}$ $\mathrm{NO}_{3}{ }^{-}, 1000 \mathrm{mg} \mathrm{L}^{-1} \mathrm{SO}_{4}{ }^{2-}, 10,000 \mathrm{mg} \mathrm{L}^{-1} \mathrm{NH}_{4}{ }^{+}$.

\subsection{Analytical Performance}

The calibration curves for each element and the correlation coefficients are presented in Table 2, together with the LOD values and LOQ values, the extraction recoveries and the enhancement factors. As it can be observed, good linearity was obtained for all elements since the correlation coefficients were above 0.999. Moreover, low LOD values $\left(0.01-0.21 \mu \mathrm{g} \mathrm{g}^{-1}\right)$ and LOQ values $\left(0.03-0.63 \mu \mathrm{g} \mathrm{g}^{-1}\right)$ were obtained. Under optimum conditions for the d-SPE method, extraction recoveries (ER \%) for Ba, $\mathrm{Cd}, \mathrm{Ni}, \mathrm{Pb}, \mathrm{Cu}$ and $\mathrm{Zn}$ ranged from 58.7 to $95.1 \%$ and enhancement factors (EFs) ranged from 12 to 19 .

Table 2. Validation results for the proposed method.

\begin{tabular}{|c|c|c|c|c|c|c|c|}
\hline Element & Calibration Curves & $\mathbf{R}$ & $\begin{array}{c}\text { Linear Range } \\
\left(\mu g g^{-1}\right)\end{array}$ & $\begin{array}{c}\text { LOD } \\
\left(\mu g g^{-1}\right)\end{array}$ & $\begin{array}{c}\mathrm{LOQ} \\
\left(\mu \mathrm{g} \mathrm{g}^{-1}\right)\end{array}$ & $\mathrm{ER}^{1 \%}$ & $\mathrm{EF}^{2}$ \\
\hline $\mathrm{Ba}$ & $y=(80.8 \pm 2.0) x-(7.6 \pm 1.2)$ & 0.9990 & $5-100$ & 0.01 & 0.03 & 73.8 & 15 \\
\hline $\mathrm{Cd}$ & $y=(68.2 \pm 1.3) x-(321.8 \pm 31.9)$ & 0.9990 & $5-500$ & 0.03 & 0.09 & 91.2 & 18 \\
\hline $\mathrm{Pb}$ & $y=(3.7 \pm 0.3) x-(180.2 \pm 10.1)$ & 0.9990 & $25-500$ & 0.21 & 0.63 & 69.3 & 14 \\
\hline $\mathrm{Ni}$ & $y=(24.5 \pm 0.3) x-(66.9 \pm 5.8)$ & 0.9996 & $5-500$ & 0.08 & 0.24 & 79.7 & 16 \\
\hline $\mathrm{Cu}$ & $y=(2551 \pm 77.9) x+(71826 \pm 363.9)$ & 0.9997 & $20-1000$ & 0.10 & 0.30 & 58.7 & 12 \\
\hline $\mathrm{Zn}$ & $y=(60.6 \pm 1.5) x+(544 \pm 37.5)$ & 0.9997 & $20-5000$ & 0.10 & 0.32 & 95.1 & 19 \\
\hline
\end{tabular}

${ }^{1}$ Extraction recovery (ER). ${ }^{2}$ Enhancement factor (EF).

The intra-day and inter-day results expressed as relative standard deviation (RSD)\% values for the toxic and nutrient metals and the RSD values for seven replicate ICP measurements of a standard solution are shown in Table 3. As it can be observed, the RSD values for the intra-day study were less than $1.9 \%$, while the inter-day values were less than $4.7 \%$. The RSD $\%$ values from the seven replicate ICP measurements of a standard solution containing the examined elements were less than $1.4 \%$ (instrumental RSD\%). Finally, relative recoveries ranged between 90.1 and $117.8 \%$ for the examined analytes.

Table 3. Intra-day and inter-day results of the proposed method.

\begin{tabular}{|c|c|c|c|c|c|c|c|c|}
\hline \multirow[b]{2}{*}{ Element } & \multirow[b]{2}{*}{ Added $(\mu \mathrm{g})$} & \multicolumn{3}{|c|}{ Intra-Day $(n=5)$} & \multicolumn{3}{|c|}{ Inter-Day $(n=5 \times 3)$} & \multirow[b]{2}{*}{$\begin{array}{c}\text { Instrumental } \\
\text { RSD }(n=7) \\
(\%)\end{array}$} \\
\hline & & $\begin{array}{c}\text { Found } \\
(\mu g)\end{array}$ & RSD $\%$ & $\begin{array}{c}\text { Relative } \\
\text { Recovery } \\
(\%)\end{array}$ & $\begin{array}{c}\text { Found } \\
(\mu g)\end{array}$ & RSD $\%$ & $\begin{array}{c}\text { Relative } \\
\text { Recovery } \\
(\%)\end{array}$ & \\
\hline $\mathrm{Ba}$ & 12.5 & $13.4 \pm 0.2$ & 1.1 & 107.4 & $14.5 \pm 0.6$ & 4.0 & 116.2 & 0.2 \\
\hline $\mathrm{Cd}$ & 12.5 & $13.5 \pm 0.1$ & 0.8 & 107.8 & $12.4 \pm 0.4$ & 3.5 & 99.0 & 0.5 \\
\hline $\mathrm{Pb}$ & 12.5 & $14.7 \pm 0.1$ & 0.6 & 117.8 & $12.6 \pm 0.4$ & 3.2 & 101.1 & 1.4 \\
\hline $\mathrm{Ni}$ & 12.5 & $13.5 \pm 0.1$ & 1.0 & 108.0 & $13.1 \pm 0.3$ & 2.6 & 104.6 & 0.6 \\
\hline $\mathrm{Cu}$ & 50 & $45.1 \pm 0.6$ & 1.3 & 90.1 & $45.7 \pm 2.2$ & 4.7 & 91.4 & 1.0 \\
\hline $\mathrm{Zn}$ & 50 & $47.2 \pm 0.9$ & 1.9 & 94.3 & $46.6 \pm 1.1$ & 2.3 & 93.1 & 0.4 \\
\hline
\end{tabular}


A comparison of the proposed method with other studies is shown in Table S4. As it can be observed, in most developed methods with graphite and graphene-oxide-derived materials, 30-200 mg of sorbent is usually required for the extraction procedure [57,59-61]. Herein, $25 \mathrm{mg}$ of NaGO was employed for the d-SPE procedure. Moreover, extraction and elution were performed within $5 \mathrm{~min}$ for each step, providing a fast and simple sample preparation method. In ref. [56], the adsorption time and desorption time were $23 \mathrm{~min}$ for each step, while in ref. [60], $10 \mathrm{~min}$ were required for the adsorption step. Compared with graphene, no chelating agents were required due to the active sites of the modified GO material [58,62]. Moreover, with the d-SPE approach there is no requirement for sorbent packing in SPE cartridges or capillary columns [53-55,57,58,60]. The RSD values and the LODs for the divalent metals are comparable to other sample preparation techniques [53-62]; however, to the best of our knowledge, that was the first study containing $\mathrm{Pb}, \mathrm{Cd}, \mathrm{Ba}, \mathrm{Zn}, \mathrm{Cu}$ and $\mathrm{Ni}$ for their extraction from meat samples.

\subsection{Reusability of the Sorbent}

Regeneration is one of the key factors for the evaluation of the performance of an adsorbent. For this purpose, the analytes were desorbed with $1.5 \mathrm{M}$ nitric acid twice, and they were not detected at the second elution fraction, indicating no carry over after the elution step. Accordingly, the reusability of the sorbent was examined. The $10 \%$ recovery loss criterion was employed to evaluate the reusability of the sorbent. The loss of the initial recovery was less than $10 \%$ for all metals, as it can be observed in Figure S2. Compared with the initial values, the recovery after 10 cycles of adsorption and desorption was between 98.3 and $108.9 \%$. As a result, with the use of $1.5 \mathrm{M}$ nitric acid as eluent and distilled water $(2 \times 10 \mathrm{~mL})$ as washing agent, the NaGO sorbent can be reused more than 10 times. The addition of water after the acidic elution is important in order to remove traces of nitric acid possibly remaining at the surface of the material, that can alter the $\mathrm{pH}$ value of the adsorption solution.

\subsection{Analysis of Real Samples}

The proposed method was successfully applied for the determination of the examined elements in meat samples (chicken, bovine and pork) obtained from local butchery shops in Thessaloniki, Greece. The results are presented in Table 4.

Table 4. Results of the analysis of meat samples from local shops.

\begin{tabular}{cccc}
\hline Element & $\begin{array}{c}\text { Chicken } \\
\left(\mu \mathrm{g} \mathrm{g}^{-1}\right)\end{array}$ & $\begin{array}{c}\text { Bovine } \\
\left(\mu \mathrm{g} \mathrm{g}^{-1}\right)\end{array}$ & $\begin{array}{c}\text { Pork } \\
\left(\mu \mathrm{g} \mathrm{g}^{-1}\right)\end{array}$ \\
\hline $\mathrm{Ba}$ & $<\mathrm{LOQ}$ & $<\mathrm{LOQ}$ & $<\mathrm{LOQ}$ \\
$\mathrm{Cd}$ & $<\mathrm{LOQ}$ & $<\mathrm{LOQ}$ & $<\mathrm{LOQ}$ \\
$\mathrm{Pb}$ & $<\mathrm{LOQ}$ & $<\mathrm{LOQ}$ & $<\mathrm{LOQ}$ \\
$\mathrm{Ni}$ & $21.1 \pm 0.3$ & $25.2 \pm 0.2$ & $22.3 \pm 0.4$ \\
$\mathrm{Cu}$ & $4.8 \pm 0.2$ & $<\mathrm{LOQ}$ & $<\mathrm{LOQ}$ \\
$\mathrm{Zn}$ & $67.0 \pm 3.2$ & $205.1 \pm 9.2$ & $55.8 \pm 3.1$ \\
\hline
\end{tabular}

\section{Conclusions}

In this work, a novel modified GO material has been prepared and used for the d-SPE of Ba, $\mathrm{Cd}, \mathrm{Cu}, \mathrm{Pb}, \mathrm{Zn}$, and $\mathrm{Ni}$ from meat samples prior to ICP-AES detection. The NaGO material shows high adsorption capacity, rapid adsorption and elution steps ( 5 min for each step), high stability in an acidic environment, reusability for at least 10 extraction-elution cycles and satisfactory selectivity when other ions are present. The proposed method is suitable for the extraction of toxic and nutrient metals from complex matrices after acidic digestion, while it shows satisfactory enrichment factors, low LOD and LOQ values, good linearity, accuracy and precision.

Supplementary Materials: The following are available online at http://www.mdpi.com/2076-3417/10/23/8722/s1, Figure S1: Pareto Charts for Ba, Cd, Ni, Cu, Zn and Pb. Figure S2. Reusability study for NaGO, Table S1: ICP-AES operating conditions and description, Table S2: Full factorial design for the optimization of experimental factors, 
Table S3: Regression analysis of the examined toxic and nutrient metals using full factorial design, Table S4: Comparison of the proposed method with other studies.

Author Contributions: Conceptualization, N.M., E.D. and G.Z.; methodology, N.M., E.D. and G.Z.; Experimental work, N.M.; data writing-original draft preparation, N.M.; writing-review and editing, E.D. and G.Z.; supervision, E.D. and G.Z. All authors have read and agreed to the published version of the manuscript.

Funding: The research work was supported by the Hellenic Foundation for Research and Innovation (HFRI) under the HFRI PhD Fellowship grant (Fellowship Number: 138).

Conflicts of Interest: The authors declare no conflict of interest.

\section{References}

1. Hidayah, N.M.S.; Liu, W.; Lai, C.; Noriman, N.Z.; Khe, C.; Hashim, U.; Lee, H.C. Comparison on graphite, graphene oxide and reduced graphene oxide: Synthesis and characterization. AIP Conf. Proc. 2017, 1892, 150002.

2. Du, J.; Cheng, H.M. The Fabrication, Properties, and Uses of Graphene/Polymer Composites. Macromol. Chem. Phys. 2012, 213, 1060-1077. [CrossRef]

3. Su, S.; Chen, B.; He, M.; Hu, B.; Xiao, Z. Determination of trace/ultratrace rare earth elements in environmental samples by ICP-MS after magnetic solid-phase extraction with $\mathrm{Fe}_{3} \mathrm{O}_{4} @ \mathrm{SiO}_{2} @$ polyaniline-graphene oxide composite. Talanta 2014, 119, 458-466. [CrossRef] [PubMed]

4. Sun, J.; Liang, Q.; Han, Q.; Zhang, X.; Ding, M. One-step synthesis of magnetic graphene oxide nanocomposite and its application in magnetic solid-phase extraction of heavy metal ions from biological samples. Talanta 2015, 132, 557-563. [CrossRef] [PubMed]

5. Liang, X.; Liu, S.; Song, X.; Zhu, Y.; Jiang, S. Layer-by-layer self-assembled graphene oxide/silica microsphere composites as stationary phase for high performance liquid chromatography. Analyst 2012, 137, 5237-5244. [CrossRef] [PubMed]

6. Wang, M.M.; Yan, X.P. Fabrication of Graphene Oxide Nanosheets Incorporated Monolithic Column via One-Step Room Temperature Polymerization for Capillary Electrochromatography. Anal. Chem. 2011, 84, 39-44. [CrossRef] [PubMed]

7. Yao, Y.; Miao, S.; Yu, S.; Ma, L.P.; Sun, H.; Wang, S. Fabrication of $\mathrm{Fe}_{3} \mathrm{O}_{4} / \mathrm{SiO}_{2}$ core/shell nanoparticles attached to graphene oxide and its use as an adsorbent. J. Colloid Interf. Sci. 2010, 379, 20-26. [CrossRef]

8. Kumara, A.S.K.; Jianga, S. Chitosan-functionalized graphene oxide: A novel adsorbent an efficient adsorption of arsenic from aqueous solution. J. Environ. Chem. Eng. 2016, 4, 1698-1713. [CrossRef]

9. Yan, J.; Chen, G.; Cao, J.; Jang, W.; Xie, B.; Yang, M. Functionalized graphene oxide with ethylenediamine and 1,6-hexanediamine. New Carbon Mater. 2012, 27, 370-376. [CrossRef]

10. Chandra, V.; Kim, K.S. Highly selective adsorption of $\mathrm{Hg}^{2+}$ by a polypyrrole-reduced graphene oxide composite. Chem. Commun. 2011, 47, 3942-3944. [CrossRef]

11. Madadrang, C.J.; Kim, H.Y.; Gao, G.; Wang, N.; Zhu, J.; Feng, H.; Gorring, M.; Kasner, M.L.; Hou, S. Adsorption Behavior of EDTA-Graphene Oxide for Pb (II) Removal. ACS Appl. Mater. Interfaces 2012, 4, 1186-1193. [CrossRef] [PubMed]

12. Ren, Y.; Yan, N.; Feng, J.; Ma, J.; Wen, Q.; Li, N.; Dong, Q. Adsorption mechanism of copper and lead ions onto graphene nanosheet $/ \delta-\mathrm{MnO}_{2}$. Mater. Chem. Phys. 2012, 136, 538-544. [CrossRef]

13. Chen, J.H.; Xing, H.T.; Sun, X.; Su, Z.B.; Huang, Y.H.; Weng, W.; Hu, S.R.; Guo, H.X.; Wu, W.B.; He, Y.S. Highly effective removal of $\mathrm{Cu}(\mathrm{II})$ by triethylenetetramine -magnetic reduced graphene oxide composite. Appl. Surf. Sci. 2015, 356, 355-363. [CrossRef]

14. Mehdinia, A.; Ramezani, M.; Jabbari, A. Preconcentration and determination of lead ions in fish and mollusk tissues by nanocomposite of $\mathrm{Fe}_{3} \mathrm{O}_{4} @$ graphene oxide@polyimide as a solid-phase extraction sorbent. Food Chem. 2017, 237, 1112-1117. [CrossRef] [PubMed]

15. Wang, B.; Zhang, F.; He, S.; Huang, F.; Peng, Z. Adsorption Behaviour of Reduced Graphene Oxide for Removal of Heavy Metal Ions. Asian J. Chem. 2014, 26, 4901-4906. [CrossRef]

16. Manousi, N.; Gomez-Gomez, B.; Madrid, Y.; Deliyanni, E.A.; Zachariadis, G.A. Determination of rare earth elements by inductively coupled plasma-mass spectrometry after dispersive solid phase extraction with novel oxidized graphene oxide and optimization with response surface methodology and central composite design. Microchem. J. 2020, 152, 104428. [CrossRef] 
17. Pastor, A.; Medina, J.; Del Ramo, J.; Torreblanca, A.; Diaz-Mayans, J.; Hernandez, F. Determination of lead in treated crayfish Procambarus clarkii: Accumulation in different tissues. Bull. Environ. Contam. Toxicol. 1988, 41, 412-418. [CrossRef]

18. Demirezen, D.; Uruç, K. Comparative study of trace elements in certain fish, meat and meat products. Meat Sci. 2006, 74, 255-260. [CrossRef]

19. Pelus, E.; Arnaud, J.; Faure, H.; Favier, A.; Roussel, A.M. Trace element (Cu, Zn, Fe, Mn, Se) intakes of a group of French men using the duplicate diet technique. Int. J. Food Sci. Nutr. 1994, 45, 63-70. [CrossRef]

20. Anthemidis, A.N.; Zachariadis, G.A.; Stratis, J.A. On-line preconcentration and determination of nickel and zinc in natural water samples by flow injection-flame atomic absorption spectrometry using PTFE-turnings for column packing. Intern. J. Environ. Anal. Chem. 2010, 90, 127-136. [CrossRef]

21. Seiler, G.; Sigel, A.; Sigel, A.H. Handbook on Metals in Clinical and Analytical Chemistry; Marcel Dekker: New York, NY, USA, 1994.

22. Momen, A.A.; Zachariadis, G.A.; Anthemidis, A.N.; Stratis, J.A. Use of fractional factorial design for optimization of digestion procedures followed by multi-element determination of essential and non-essential elements in nuts using ICP-AES technique. Talanta 2007, 71, 443-451. [CrossRef] [PubMed]

23. López-Alonso, M.; Miranda, M.; Castillo, C.; Hernández, J.; García-Vaquero, M.; Benedito, J.L. Toxic and essential metals in liver, kidney and muscle of pigs at slaughter in Galicia, north-west Spain. Food Addit. Contam. 2007, 24, 943-954. [CrossRef] [PubMed]

24. Alcaide-Castineira, E.; Gomez, R.; Carmona-Gonzalez, M.A.; Fernandez-Salgvero, J. Study of minerals in meat products. Alimentaria 1995, 262, 63-67.

25. Demirbaş, A. Proximate and heavy metal composition in chicken meat and tissues. Food Chem. 1999, 67, 27-31. [CrossRef]

26. Papadomichelakis, G.; Zoidis, E.; Pappas, A.C.; Danezis, G.; Georgiou, C.A.; Fegeros, K. Dietary organic selenium addition and accumulation of toxic and essential trace elements in liver and meat of growing rabbits. Meat Sci. 2018, 145, 383-388. [CrossRef]

27. Falandysz, J. Manganese, copper, zinc, iron, cadmium, mercury and lead in muscle meat, liver and kidneys of poultry, rabbit and sheep slaughtered in the northern part of Poland, 1987. Food Addit. Contam. 1991, 8, 71-83. [CrossRef]

28. Little, T.A. Design of experiment is a powerful development tool for method characterization and method validation. BioPharm Int. 2014, 27, 40-45.

29. Zacharis, C.K.; Vastardi, E. Application of analytical quality by design principles for the determination of alkyl p-toluenesulfonates impurities in Aprepitant by HPLC. Validation using total-error concept. J. Pharm. Biomed. Anal. 2017, 150, 152-161. [CrossRef]

30. Escudero, L.A.; Cerutti, S.; Olsina, R.A.; Salonia, J.A.; Gasquez, J.A. Factorial design optimization of experimental variables in the on-line preparation/preconcentration of copper in water samples using solid-phase extraction and ICP-AES determination. J. Hazard. Mater. 2010, 183, 218-223. [CrossRef]

31. Zachariadis, G.A.; Archontas, K.N. The Potential of Desirability Function Strategy in Chemometric Optimization of ICP-AES for Platinum Group Elements and Gold. Curr. Anal. Chem. 2016, 12, 147-158. [CrossRef]

32. Derringer, G.; Suich, R. Simultaneous Optimization of Several Response Variables. J. Qual. Technol. 1980, 12, 214-219. [CrossRef]

33. Hummers, W.S.; Offeman, R.E. Preparation of Graphitic Oxide. J. Am. Chem. Soc. 1958, 80, 1339. [CrossRef]

34. Stankovich, S.; Dikin, D.A.; Piner, R.D.; Kohlhaas, K.A.; Kleinhammes, A.; Jia, Y.Y. Synthesis of graphene-based nanosheets via chemical reduction of exfoliated graphite oxide. Carbon 2007, 45, 1558-1565. [CrossRef]

35. Karageorgou, E.; Samanidou, V. Youden test application in robustness assays during method validation. J. Chromatogr. A 2014, 1351, 131-139. [CrossRef] [PubMed]

36. Yousefi, S.R.; Shemirani, F.; Jamali, M.R. Continuous pressurized solvent extraction of polycyclic aromatic hydrocarbons from biosolids. Assessment of their lability in soils amended with biosolids. Anal. Lett. 2010, $16,2465-2476$.

37. Jeong, H.K.; Noh, H.J.; Kim, J.Y.; Jin, M.H.; Park, C.Y.; Lee, Y.H. X-ray absorption spectroscopy of graphite oxide. EPL 2008, 82, 1-5. [CrossRef] 
38. Seredych, M.; Tamashausky, A.V.; Bandosz, T.J. Graphite oxides obtained from porous graphite: The role of surface chemistry and texture in ammonia retention at ambient conditions. Adv. Funct. Mater. 2010, 20, 1670-1679. [CrossRef]

39. Foo, K.Y.; Hameed, B.H. Preparation of activated carbon from date stones by microwave induced chemical activation: Application for methylene blue adsorption. Chem. Eng. J. 2011, 170, 338-341. [CrossRef]

40. Krishnan, K.A.; Anirudhan, T.S. Kinetic and equilibrium modeling of cobalt(ii) adsorption onto bagasse pith based sulphurised activated carbon. Chem. Eng. J. 2008, 137, 257-264. [CrossRef]

41. Vukovic, G.D.; Marinkovic, A.D.; Skapin, S.D.; Ristic, M.D.; Aleksic, R.; Peric-Grujic, A.A.; Uskokovic, P.S. Removal of lead from water by amino modified multi-walled carbon nanotubes. Chem. Eng. J. 2011, 173, 855-865. [CrossRef]

42. Rivera-Utrilla, J.; Sánchez-Polo, M. Adsorption of $\mathrm{Cr}$ (III) on ozonised activated carbon. Importance of Cpi-cation interactions. Water Res. 2003, 37, 3335-3340. [CrossRef]

43. Giannakoudakis, D.A.; Mitchell, J.K.; Bandosz, T.J. Reactive adsorption of mustard gas surrogate on zirconium (hydr)oxide/graphite oxide composites: The role of surface and chemical features. J. Mat. Chem. A 2016, 4, 1008-1019. [CrossRef]

44. Socrates, G. Infrared Characteristic Group Frequencies, 2nd ed.; John Wiley \& Sons: New York, NY, USA, 1994.

45. Giannakoudakis, D.A.; Bandosz, T.J. Zinc (hydr)oxide/graphite oxide/AuNPs composites: Role of surface features in $\mathrm{H}_{2} \mathrm{~S}$ reactive adsorption. J. Colloid Interface Sci. 2014, 436, 296-305. [CrossRef] [PubMed]

46. Dreyer, D.R.; Park, S.; Bielawski, C.W.; Ruoff, R.S. The chemistry of graphene oxide. Chem. Soc. Rev. 2010, 39, 228-240. [CrossRef]

47. Deliyanni, E.; Arabatzidou, A.; Tzoupanos, N.; Matis, K.A. Adsorption of $\mathrm{Pb}^{2+}$ Using Mesoporous Activated Carbon and Its Effects on Surface Modifications. Adsorpt. Sci. Technol. 2012, 30, 627-645. [CrossRef]

48. Myglovets, M.; Poddubnaya, O.I.; Sevastyanova, O.; Lindström, M.E.; Gawdzik, B.; Sobiesiak, M.; Tsyba, M.M.; Sapsay, V.I.; Klymchuk, D.O.; Puziy, A.M. Preparation of carbon adsorbents from lignosulfonate by phosphoric acid activation for the adsorption of metal ions. Carbon 2014, 80, 771-783. [CrossRef]

49. Kyzas, G.Z.; Deliyanni, E.A.; Matis, K.A. Activated carbons produced by pyrolysis of waste potato peels: Cobalt ions removal by adsorption. Colloids. Surf. A 2016, 490, 74-83. [CrossRef]

50. Kyzas, G.Z.; Deliyanni, E.A.; Mitropoulos, A.C.; Matis, K.A. Hydrothermally produced activated carbons from zero-cost green sources for cobalt ions removal. Desalin. Water Treat. 2018, 123, 288-299. [CrossRef]

51. Bibaj, E.; Lysigaki, K.; Nolan, J.W.; Seyedsalehi, M.; Deliyanni, E.A.; Mitropoulos, A.C.; Kyzas, G.Z. Activated carbons from banana peels for the removal of nickel ions. Int. J. Environ. Sci. Technol. 2019, 16, 667-680. [CrossRef]

52. Angel Maqulelra, H.A.M.E.; Puchades, R. Use of Saccharomyces cerevisiae in Flow Injection Atomic Absorption Spectrometry for Trace Metal Preconcentration. Anal. Chem. 1994, 66, 3632-3638.

53. Su, S.; Chen, B.; He, M.; Hu, B. Graphene oxide-silica composite coating hollow fiber solid-phase microextraction online coupled with inductively coupled plasma mass spectrometry for the determination of trace heavy metals in environmental water samples. Talanta 2014, 123, 1-9. [CrossRef] [PubMed]

54. Hu, W.; Hu, B.; Jiang, Z.C. On-line preconcentration and separation of Co, Ni and Cd via capillary microextraction on ordered mesoporous alumina coating and determination by inductively plasma mass spectrometry (ICP-MS). Anal. Chim. Acta 2006, 572, 55-62. [CrossRef] [PubMed]

55. Zheng, F.; Hu, B. MPTS-silica coated capillary microextraction on line hyphenated with inductively coupled plasma atomic emission spectrometry for the determination of $\mathrm{Cu}, \mathrm{Hg}$ and $\mathrm{Pb}$ in biological samples. Talanta 2007, 73, 372-379. [CrossRef] [PubMed]

56. Behbahani, M.; Salarian, M.; Bagheri, A.; Tabani, H.; Omidi, F.; Fakhari, A. Synthesis, characterization and analytical application of $\mathrm{Zn}$ (II)-imprinted polymer as an efficient solid-phase extraction technique for trace determination of zinc ions in food samples. J. Food. Compos. Anal. 2014, 34, 81-89. [CrossRef]

57. Sitko, R.; Zawisza, B.; Talik, E.; Janik, P.; Osoba, G.; Feist, B.; Malicka, E. Spherical silica particles decorated with graphene oxide nanosheets as a new sorbent in inorganic trace analysis. Anal. Chim. Acta 2014, 834, 22-29. [CrossRef]

58. Pourjavid, M.; Arabieh, M.; Yousefi, S.; Jamali, M.; Rezaee, M.; Hosseini, M.; Sehat, A. Study on column SPE with synthesized graphene oxide and FAAS for determination of trace amount of $\mathrm{Co}(\mathrm{II})$ and $\mathrm{Ni}(\mathrm{II})$ ions in real samples. Mat. Sci. Eng. C 2015, 47, 114-122. [CrossRef] 
59. Yavuz, E.; Tokalıoğlu, S.; Sxahan, H.; Patat, S.A. A graphene/ $\mathrm{Co}_{3} \mathrm{O}_{4}$ nanocomposite as a new adsorbent for solid phase extraction of $\mathrm{Pb}(\mathrm{II}), \mathrm{Cu}(\mathrm{II})$ and $\mathrm{Fe}(\mathrm{III})$ ions in various samples. RSC Adv. 2013, 3, 24650-24657. [CrossRef]

60. Sayar, O.; Mehrani, K.; Hoseinzadeh, F.; Mehrani, A.; Sadeghi, O. Comparison of the performance of different modified graphene oxide nanosheets for the extraction of $\mathrm{Pb}$ (II) and $\mathrm{Cd}(\mathrm{II})$ from natural samples. Microchim. Acta 2014, 181, 313-320. [CrossRef]

61. Zheng, H.; Jia, B.; Zhu, Z.; Tang, Z.; Hu, S. Determination of trace amounts of Pb, Cd, Ni and Co by wavelength-dispersive Xray fluorescence spectrometry after preconcentration with dithizone functionalized graphene. Anal. Methods 2014, 6, 8569-8576. [CrossRef]

62. Kocot, K.; Sitko, R. Trace and ultratrace determination of heavy metal ions by energy-dispersive X-ray fluorescence spectrometry using graphene as solid sorbent in dispersive micro solid-phase extraction. Spectrochim. Acta B 2014, 94-95, 7-13. [CrossRef]

Publisher's Note: MDPI stays neutral with regard to jurisdictional claims in published maps and institutional affiliations.

(C) 2020 by the authors. Licensee MDPI, Basel, Switzerland. This article is an open access article distributed under the terms and conditions of the Creative Commons Attribution (CC BY) license (http://creativecommons.org/licenses/by/4.0/). 